\title{
Selecting geomorphic variables for automatic river segmentation: Trade-offs between information gained and effort required
}

\author{
Vanesa Martínez-Fernández *, Marta González del Tánago, Diego García de Jalón \\ Department of Natural Systems and Resources, E.T.S. Ingeniería de Montes, Forestal y del Medio Natural, Universidad Politécnica de Madrid, Ciudad Universitaria s/n, 28040 Madrid, Spain
}

\section{A R T I C L E I N F O}

\section{Article history:}

Received 6 August 2018

Received in revised form 3 January 2019

Accepted 4 January 2019

Available online 16 January 2019

\section{Keywords:}

River segmentation

Geomorphic variables

Multi-response-permutation procedures

Flow regulation

\begin{abstract}
A B S T R A C T
Identifying river segments with apparently distinct geomorphic characteristics but relatively homogeneous internal features may be critically helpful in designing network analysis for characterization, environmental assessment and river management. Automatic segmentation procedures using geographic tools and statistical methods provide objective and replicable results. In particular, multivariate procedures may be appropriated for different purposes such as coping with the multiple dimensionality of river systems. Although there is an increasing number of studies dealing with segmentation using different sets of morphological variables, the influence that the selected variables have on segmentation results is rarely assessed. In this context, we defined five combinations of frequently used geomorphic variables (i.e., channel slope, active channel width, valley bottom width, channel confinement and specific stream power), and compared the obtained segmentation results. We study the upper Esla River network, covering a total length of $294 \mathrm{~km}$, with the largest two rivers regulated by large dams. Variables were measured at successive river sections $200 \mathrm{~m}$ apart. Five segmentation results were obtained in which we compared the number and characteristics of the segments, and the internal variability and the suitability of predicting river dynamics (i.e., occurrence of bare and vegetated gravel bars). The number of segments per kilometer of river and their average length were different among segmentations but varied much more across rivers than across segmentations. In general, segmentations including channel slope and active channel width performed better in predicting the occurrence of bare gravel bars than segmentations based on stream power or valley confinement. When splitting the initial data set into regulated and non-regulated segments, differences in predicting the occurrence of gravel bars were found, with better results in the case of non-regulated rivers. Channel slope and active channel width showed a reduced explanatory power for the regulated reaches. Finally, we conclude that primary geomorphic variables such as channel slope and active channel width were more efficient than secondary variables such as stream power, which may encompass more information but needed additional data and the use of empirical models, with greater effort and much uncertainty. In the case of regulated rivers, automatic segmentation including the affected variables (e.g., active channel width) may help in detecting differences in geomorphic sensitivity to river adjustments across the resulting segments downstream from the dams. Our results offer valuable insights into the selection of geomorphic variables for river segmentation analysis, in which trade-offs between the information gained and the effort required must be considered according to the respective research targets.
\end{abstract}

(c) 2019 Elsevier B.V. All rights reserved.

\section{Introduction}

In river studies, identifying river segments with distinct geomorphic characteristics but with relatively homogeneous features internally may be very useful to carry out geomorphic characterization and classification analysis (Rinaldi et al., 2016; González del Tánago et al., 2016a), environmental assessments (Rinaldi et al., 2013) or restoration design (Beechie et al., 2010). The utility of delineating uniform segments within which the river maintains a relatively consistent internal set

\footnotetext{
* Corresponding author.

E-mail address: vanesa.mfernandez@upm.es (V. Martínez-Fernández).
}

of process-form interactions has been underlined by many authors (Brierley and Fryirs, 2005; Reid and Brierley, 2015; Gurnell et al., 2016). Traditionally, the recognition of these relatively uniform river segments was accomplished visually by expert criteria, based on different structure attributes or functional processes (Frissell et al., 1986; Montgomery, 1999; Habersack, 2000, Benda et al., 2004, Seelbach et al., 2006). However, in recent years, automatic segmentation procedures using geographic tools and statistical methods have been developed that provide more objective and replicable results in defining discreteness along the river continuum (Piégay et al., 2012). These automatic procedures identify longitudinal discontinuities through the river network according to statistically significant variations in certain variables, and can be univariate, based on one single variable 
(e.g., Leviandier et al., 2012; Parker et al., 2012; Guertault et al., 2018), or multivariate, based on several variables considered simultaneously (e.g., Orlowski et al., 1993; Brenden et al., 2008; Bizzi and Lerner, 2012; Schmitt et al., 2014; Martínez-Fernández et al., 2016b). The number of variables potentially used in multivariate segmentation procedures has increased considerably due to the overwhelming availability of information and the continuing increase in the number of new sophisticated tools and data mining techniques (see Carbonneau and Piégay, 2012, Demarchi et al., 2017; Rivas Casado et al., 2017).

Geomorphic variables such as valley and active channel width (Alber and Piégay, 2011; Martínez-Fernández et al., 2016b), Strahler order (Bizzi and Lerner, 2012), channel slope or channel confinement (Schmitt et al., 2014; Yochum et al., 2017) have been used frequently for river segmentation. These physical variables, hereinafter referred to primary variables, provide valuable insight into river morphology and may be directly extracted with moderate effort from highresolution digital information (such as digital elevation models or aerial photographs), which in many cases are also available for a long sequence of years that allow for temporal analysis. Additionally, other geomorphic variables such as stream power (Reinfelds et al., 2004; Schmitt et al., 2014) or sediment transport capacity (Parker et al., 2012) are being increasingly considered for automatic river segmentation. These more complex variables, hereinafter referred to secondary variables, are not directly extracted from digital elevation models or aerial photographs and require hydrological data and the use of empirical models, which makes them more time-consuming to determine and involves uncertainty in their quantification.
In previous research, we compared the advantages and performance of univariate versus multivariate procedures using geomorphic variables for automatic segmentation of rivers (Martínez-Fernández et al., 2016b). The purpose of this paper is to explore the influence of the selected set of variables included in the multivariate analysis on the obtained river segments. We hypothesize that segmentation performance should improve when considering a higher number of variables with higher complexity. To test this hypothesis, we assessed the utility of secondary variables whose extraction required a considerable calculation effort based on other variables (e.g., specific stream power) versus the use of other primary variables that are directly extracted from digital elevation models or aerial photographs (i.e., whose use involves much less effort and uncertainty). We evaluated the influence of the selected set of variables by analysing the differences across segmentations in (1) the number and characteristics of the obtained segments, (2) the general and internal variability within the segment (i.e., aggregated) data set in relation to variability of the initial (i.e., non-aggregated) data set, (3) the suitability to predict the proportion of bare and vegetated gravel bars, and (4) the influence of flow regulation by large dams on segmentation results.

\section{Methodology}

\subsection{Study site}

The study was carried out along the river network of the Upper Esla Basin, in northwestern Spain (Fig. 1), and includes the upper part

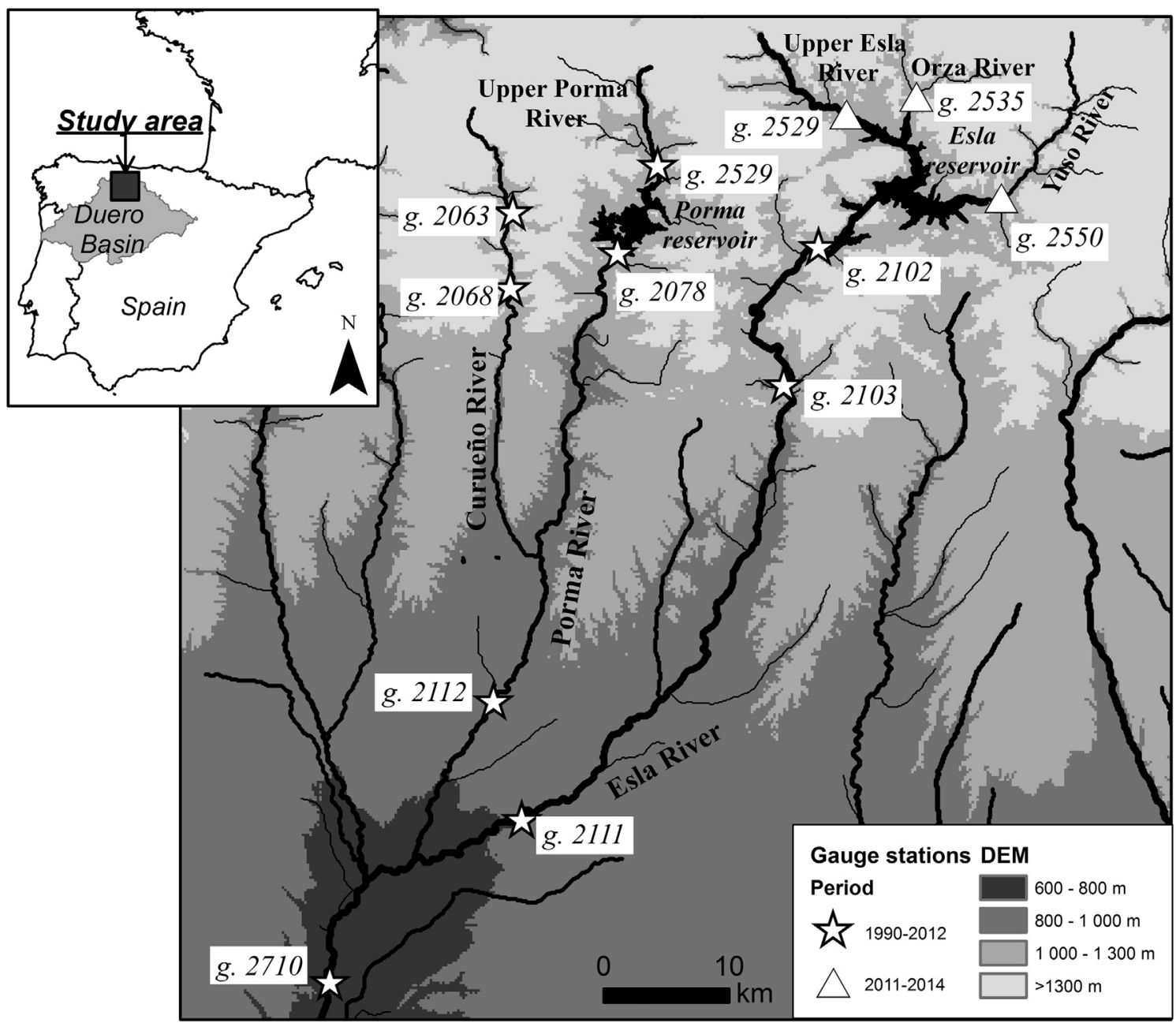

Fig. 1. Location of the study area showing the location of gauging stations. 
Table 1

Flow regime characteristics of the studied rivers measured along the period indicated for each gauge station shown in Fig. 1.

\begin{tabular}{lllll}
\hline River/segment & $\begin{array}{l}\text { Regulation } \\
\text { status }\end{array}$ & $\begin{array}{l}\text { Gauge } \\
\text { stations } \\
\text { (codes) }\end{array}$ & $\begin{array}{l}\text { Considered } \\
\text { period }\end{array}$ & $\begin{array}{l}\text { Annual maximum flow } \\
\left.\text { (Median values, } \mathrm{m}^{3} / \mathrm{s}\right)\end{array}$ \\
\hline Upper Porma & Non-regulated & 2078 & $1988-2012$ & 32.3 \\
Upper Esla & Non-regulated & 2529 & $2011-2014$ & 36.3 \\
Orza & Non-regulated & 2535 & $2011-2014$ & 30.1 \\
Yuso & Non-regulated & 2550 & $2011-2014$ & 50.2 \\
Curueño & Non-regulated & 2063 & $2000-2012$ & 26.3 \\
Porma & & 2068 & $1988-2012$ & 31.8 \\
& Regulated & 2011 & $1988-2012$ & 23.0 \\
Esla (studied) & (since 1968) & 2112 & $1988-2012$ & 69.6 \\
& Regulated & 2102 & $1988-2012$ & 54.7 \\
& (since 1988) & 2103 & $1988-2012$ & 71.9 \\
& & 2111 & $1988-2012$ & 92.3 \\
& & 2710 & $1988-2012$ & 280.5 \\
\hline
\end{tabular}

of the Esla River and its tributaries, the Orza and Yuso rivers, and the Porma River with its tributary the Curueño River. The studied fluvial network represents a total length of approximately $294 \mathrm{~km}$. The Esla River is regulated by a large dam operating since 1988 , with a storage capacity for nearly $90 \%$ of the natural runoff. The Porma River is also regulated by a large dam operating since 1968 , with a storage capacity for $106 \%$ of the natural runoff, whereas the rest of the rivers are non-regulated.

All the rivers have a pattern typical of high-energy gravel-bed rivers. Most of the headwater reaches have relatively narrow channels with predominantly straight planform. Downstream reaches tend to become pseudomeandering in the larger rivers, (i.e., the Porma and Esla rivers) and wandering in the smaller ones (i.e., the Curueño and Yuso rivers). Average annual flows range from 2.5 to $22 \mathrm{~m}^{3} / \mathrm{s}$ in the recent period (1988-2014) and the main flow regime characteristics of the studied rivers are shown in Table 1.

\subsection{Geomorphic variables}

Five geomorphic variables were used to segment the studied fluvial network: channel slope, active channel width, valley bottom width, channel confinement and specific stream power. We designed five combinations of these variables following an increasing gradient of time consumed in variable data collection. Table 2 shows these combinations of variables together with the data source and the calculations needed. We combined information extracted from a digital elevation model (DEM) with a spatial resolution of $5 \mathrm{~m}$, dated 2010 (www.ign.es), with information extracted from orthophotographs with a spatial resolution of $0.25-0.5 \mathrm{~m}$, dated 2011.

All variable measurements were systematically collected every $200 \mathrm{~m}$ along the valley axis following the approach of MartínezFernández et al. (2016b). The $200 \mathrm{~m}$ interval was decided arbitrarily, but similar intervals were used in previous studies with data that had high spatial resolution and analogous purposes (e.g., Alber and Piégay, 2011; Bizzi and Lerner, 2012). We manually digitized the active channel and valley bottom of the entire studied river network on the orthophotographs, taking into consideration visual fluvial features and valley cross sections. Active channel width and valley bottom width were directly measured at each interval of $200 \mathrm{~m}$ on the resulting polygons. Channel slope $(S)$ was calculated over constant lengths of $1 \mathrm{~km}$ (i.e., slope was calculated as the elevation difference between one point and the point located $1 \mathrm{~km}$ upstream divided by the channel length between those points), because this results in a more robust representation of fluvial conditions than local measurements every $200 \mathrm{~m}$ (Bizzi and Lerner, 2012). Channel confinement (C) was defined as the ratio of valley bottom width to active channel width. Calculation of the specific stream power $(\omega)$ required previous analysis of discharge series. Specific stream power is defined as:

$\omega=\frac{\gamma Q s}{w}$

where $\gamma$ is the specific weight of water $\left(=9800 \mathrm{~N} \mathrm{~m}^{-3}\right), Q$ is water discharge $\left(\mathrm{m}^{3} / \mathrm{s}\right), \mathrm{s}$ is the energy slope $\left(\mathrm{m} \mathrm{m}^{-1}\right)$ that may be approximated by the slope of the channel bed (Knighton, 1999), and $w$ is the channel width $(\mathrm{m})$. For $Q$ we used the median of annual maximum flows (Jain et al., 2006). From the available gauge stations, we interpolated values every $200 \mathrm{~m}$ in the entire river network following procedures similar to those proposed by Bizzi and Lerner (2012) and Schmitt et al. (2014). We used the power law regression with drainage area (Knighton, 1999):

Qmed $=a A d^{b}$

where Ad is the drainage area of every downstream point in each $200 \mathrm{~m}$ reach, and $a$ and $b$ are the regression coefficients. We calculated the median values of annual maximum flows for gauge stations and periods. The power regression between median values of annual maximum flows and drainage area was established using information from all 12 gauge stations in the basin $\left(Q_{\text {med }}=2.30 A d^{0.52}, R^{2}=0.85\right)$. Finally, the specific stream power was calculated every $200 \mathrm{~m}$ using the active channel width and channel slope previously measured, and the respective median value of annual maximum flow interpolated every $200 \mathrm{~m}$. The GIS analysis was supported by ESRI ArcMap version 10.3, with the ArcHydrotools, 3DAnalysis, Spatial Analyst, and XtoolsPro extensions.

\subsection{Segmentation procedure}

Similar multivariate analyses by multi-response permutation procedures (MRPP) (Mielke, 1991) were applied to the five segmentation runs considered in our study (see Table 2). The MRPP are nonparametric techniques that allow the system (i.e., the river network) to be classified into homogeneous and significantly different groups (i.e., river segments), and, at the same time, they have the advantage of considering the multivariate dimension of the studied system (Orlowski et al., 1993). The MRPP statistic quantifies the separation between groups by considering the objects in a Euclidian data space. This statistic is calculated as the weighted average of the within-group betweenpoint average Euclidean distance, indicating in the case of small values a tendency for clustering.

The MRPP were demonstrated to be suitable for river segmentation, as they provide nearly stable locations of break points under alpha risk

Table 2

Combination of geomorphic variables defined for segmentation comparisons, covering a gradient of needed effort for data mining.

\begin{tabular}{|c|c|c|}
\hline Segmentation runs & Geomorphic variables & Data source \\
\hline S1 & Active channel width, channel slope & Aerial photographs, DEM \\
\hline S2 & Active channel width, channel slope, Valley bottom width & Aerial photographs, DEM \\
\hline S3 & Active channel width, channel confinement & Aerial photographs, DEM, calculation of ratio active channel width/valley bottom width \\
\hline S4 & Specific stream power, channel confinement, & Aerial photographs, DEM, discharge data, calculation of W \\
\hline S5 & Specific steam power, valley bottom width & $\begin{array}{l}\text { Aerial photographs, DEM, discharge data, calculation of W, calculation of ratio active } \\
\text { channel width/valley bottom width }\end{array}$ \\
\hline
\end{tabular}


changes (alpha ranging from 0.05 to 0.001 ) and better behaviour with longitudinal repeatability than other tests (Martínez-Fernández et al., 2016b). Additionally, MRPP have the advantage of representing an integrative approach capable of considering the complexity of the geomorphic river context aggregating the information that multiple variables provide. The geomorphic variables were standardized in each river before applying the algorithm following Martínez-Fernández et al. (2016b). In this case, an alpha risk of 0.01 was considered instead of 0.05 , as little variations or no differences in the number of segments were observed in most of the studied rivers (i.e., only the Esla River yielded a larger number of segments when 0.05 was considered; results not shown). It falls beyond the scope of this paper to test different $p$-values, but in any case, 0.01 is a more exigent value and provides a more robust final segmentation. Two consecutive breakpoints detected by the respective segmentation method defined a river segment.

\subsection{Data analysis}

After applying the five segmentation analyses explained above (S1 to S5, see Table 2), we searched for relevant differences between them regarding the influence of the set of geomorphic variables.

\subsubsection{Number and characteristics of obtained segments}

We compared the results from the five segmentations in terms of the number of segments, their average length and the spatial coincidence across the resultant river segments. For this latter purpose, we analysed similarities in the location of breakpoints detected by the respective five segmentations $\mathrm{S} 1$ to $\mathrm{S} 5$ by assessing the number of coincidences between segmentations and analysing differences with the Kruskal-Wallis test (Kruskal and Wallis, 1952). Additionally, correlation matrices between measured variables were calculated for each river and for the entire fluvial network (Spearman test) to better understand the differences in the number and characteristics of segments differentiated by the five river segmentations (S1 to S5).

\subsubsection{General variability and internal homogeneity of segments}

We analysed whether the internal variation within the segments was in fact reduced, searching for differences across segmentations. To that purpose, we quantified the internal variability of segments $\left(\mathrm{CV}_{\text {intra }}\right)$ (i.e., the coefficient of variation within each segment), and its reduction in relation to the variability of the initial data set was calculated as the ratio: $\left(\mathrm{CV}_{\text {non-aggreg }}-\mathrm{CV}_{\text {intra }}\right) / \mathrm{CV}_{\text {non-aggreg, }}$ where $\mathrm{CV}_{\text {non-aggreg }}$ is the coefficient of variation of the initial non-aggregated data set (i.e., data set of 200-m-long units).

Although segmentation procedures are likely to reduce the variation in the data set (Livingstone, 2009), they should additionally conserve the original variation as much as possible (Schmitt et al., 2014). To explore which segmentation performance was better at maintaining the total variability of the initial data set, we evaluated the variability reduction in each obtained segmentation as the ratio $\mathrm{CV}_{\text {aggreg }} / \mathrm{CV}_{\text {non-aggreg, }}$ where $\mathrm{CV}_{\text {aggreg }}$ is the coefficient of variation of the aggregated data set, and searched for differences across approaches (S1-S5). The higher the ratio, the more adequate the segmentation procedure is at avoiding oversimplification of the initial variability.

\subsubsection{Suitability of segmentations to predict bare and vegetated gravel bars}

Additionally, we seek to quantify to what extent the resultant segmentations could be related to the geomorphic dynamism of the studied rivers, in our case informed by the formation of bare and vegetated gravel bars, and which of them provided better results. In this case, a numerical model experiment was designed to evaluate if the derived segmentations were significantly correlated with the occurrence of in-channel geomorphic units (i.e., bare gravel bars and vegetated bars). These types of geomorphic units have been recognized as strong indicators of morphological processes and functioning status in gravel bed rivers, especially under flow regulation by large dams (Lobera et al., 2015; González del Tánago et al., 2016b; Martínez-Fernández et al., 2017). We calculated the proportion of these geomorphic units in each initial $200 \mathrm{~m}$ unit by counting their presence or absence in three transversal sections equally spaced within the respective $200 \mathrm{~m}$ length. Then, we aggregated the information extracted from the $200 \mathrm{~m}$ long units belonging to the same segments that resulted from each segmentation (S1 to S5), and following an analogous approach we characterized each segment by the average proportion of both types of geomorphic units (i.e., bare gravel and vegetated bars).

Generalized additive models (GAMs) (Faraway, 2006) were run to evaluate the relationship between the resulting segmentations S1 to S5 and the proportions of bare gravel and vegetated bars observed in each segmentation, considering quasibinomial errors to avoid overdispersion (Zuur et al., 2009). In each model run, only the variables used in each segmentation were considered to explore relationships with geomorphic units (e.g., for S1 only channel slope and active channel width were considered to explore the relationship with bare gravel and vegetated bars). GAMs were also run with the non-aggregated dataset (units $200 \mathrm{~m}$ long) to benchmark against models using the aggregated dataset. The resulting models were compared using the percentage of the deviance explained by each model.

\subsubsection{Flow regulation influence on segmentation results}

Finally, we explored the effects that flow regulation by dams and reservoirs could have that lead to different segmentation results and alter the ability of models to predict the occurrence of gravel bars. On one hand, we considered three different sets of segments to detect the effects of flow regulation on GAM results across different segmentation approaches: (1) all segments in the study area, (2) only segments of non-regulated rivers, and (3) only segments of regulated rivers. On the other hand, the impoundment ratio (i.e., the ratio between reservoir capacity and annual runoff, this value being equal to zero in nonregulated rivers) was considered as an additional variable in the GAM runs. This new variable was calculated at each important river confluence.

All the analyses were conducted using $R$ v. 3.3.3 software ( $R$ Development Core Team, 2017). The function kruskal.test and cor.test of package stats were used to run the Kruskal-Wallis test and obtain the Spearman correlations, respectively, and the function gam of package $m g c v$ (Wood, 2015) was used to run the generalized additive models.

\section{Results}

\subsection{Differences in number and characteristics of the segments}

Each segmentation run discriminated different numbers of river segments along the studied fluvial network (Table 3, see Figs. 2 and 3 for the Porma and Yuso River examples; see Supplementary Figs. S1-S2 for more examples). The simplest one (i.e., S1, using channel slope and active channel width) differentiated 60 segments in the entire studied area, representing the smallest number of segments characterized by the highest variability in their lengths. On the other side, one of the most time-consuming procedures (i.e., S5 including specific stream power) resulted in 95 segments, providing the largest number of segments with intermediate length variability.

The specific number of segments (i.e., number of segments per $\mathrm{km}$ of river) and their average lengths varied much more across rivers than across segmentations, with significant differences among rivers (Kruskal-Wallis test, $p<0.01$ ) but not among segmentations (KruskalWallis test, $p>0.1$ ) (Table 3 ). In the smaller rivers (i.e., Upper Porma, Upper Esla and Orza rivers), S1 and S2 showed higher differences between them, with S2 providing the highest number of segments per $\mathrm{km}$, whereas S3, S4 and S5 were more similar. In the longer rivers (i.e., the Esla and Porma rivers) the number of segments per km 
Table 3

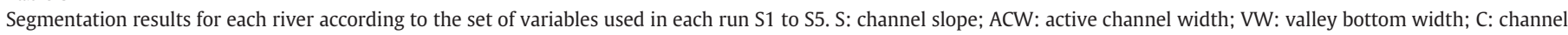
confinement; W specific stream power; N: number of segments; L (km): average length of segments. CV L: coefficient of variation of the length of segments.

\begin{tabular}{|c|c|c|c|c|c|c|c|c|c|}
\hline Rivers & & Upper Porma & Upper Esla & Orza & Yuso & Curueño & Esla & Porma & Total \\
\hline S1 & $\mathrm{N}$ & 2 & 3 & 4 & 7 & 11 & 18 & 15 & 60 \\
\hline \multirow[t]{3}{*}{$(\mathrm{S}, \mathrm{ACW})$} & $\mathrm{N} / \mathrm{km}$ & 0.34 & 0.26 & 0.38 & 0.41 & 0.26 & 0.20 & 0.29 & \\
\hline & $\mathrm{L}(\mathrm{km})$ & 2.9 & 3.8 & 2.6 & 2.4 & 3.9 & 5 & 3.5 & \\
\hline & CV L & 0.94 & 0.64 & 0.58 & 0.4 & 0.98 & 1.04 & 0.86 & \\
\hline S2 & $\mathrm{N}$ & 4 & 5 & 7 & 6 & 14 & 28 & 23 & 87 \\
\hline \multirow{3}{*}{$(\mathrm{S}, \mathrm{ACW}, \mathrm{VW})$} & $\mathrm{N} / \mathrm{km}$ & 0.69 & 0.44 & 0.67 & 0.35 & 0.33 & 0.31 & 0.44 & \\
\hline & $\mathrm{L}(\mathrm{km})$ & 1.5 & 2.3 & 1.5 & 2.8 & 3 & 3.2 & 2.3 & \\
\hline & CV L & 0.42 & 0.42 & 0.25 & 0.39 & 0.68 & 1.17 & 0.65 & \\
\hline S3 & $\mathrm{N}$ & 3 & 5 & 5 & 6 & 12 & 19 & 16 & 66 \\
\hline \multirow[t]{3}{*}{$(S, C)$} & $\mathrm{N} / \mathrm{km}$ & 0.52 & 0.44 & 0.48 & 0.35 & 0.28 & 0.21 & 0.30 & \\
\hline & $\mathrm{L}(\mathrm{km})$ & 1.9 & 2.3 & 2.1 & 2.8 & 3.5 & 4.7 & 3.3 & \\
\hline & CV L & 0.86 & 0.35 & 0.48 & 0.37 & 0.68 & 0.97 & 0.71 & \\
\hline S4 & $\mathrm{N}$ & 3 & 4 & 7 & 5 & 13 & 27 & 18 & 75 \\
\hline \multirow[t]{3}{*}{$(\mathrm{C}, \omega)$} & $\mathrm{N} / \mathrm{km}$ & 0.52 & 0.35 & 0.48 & 0.29 & 0.31 & 0.30 & 0.34 & \\
\hline & $\mathrm{L}(\mathrm{km})$ & 1.9 & 2.8 & 2.1 & 3.4 & 3.3 & 3.3 & 2.9 & \\
\hline & CV L & 0.86 & 0.06 & 0.57 & 0.98 & 0.67 & 0.65 & 0.71 & \\
\hline S5 & $\mathrm{N}$ & 3 & 3 & 7 & 8 & 16 & 37 & 23 & 95 \\
\hline \multirow[t]{3}{*}{$(\mathrm{VW}, \omega)$} & $\mathrm{N} / \mathrm{km}$ & 0.52 & 0.26 & 0.48 & 0.47 & 0.38 & 0.41 & 0.44 & \\
\hline & $\mathrm{L}(\mathrm{km})$ & 1.9 & 3.8 & 2.1 & 2.1 & 2.7 & 2.4 & 2.3 & \\
\hline & CV L & 0.60 & 0.45 & 0.52 & 0.46 & 0.59 & 0.71 & 0.67 & \\
\hline
\end{tabular}

exhibited less variation across segmentations and S5 differentiated more segments per $\mathrm{km}$.

To explain differences and similarities across segmentations using different set of geomorphic variables, correlation among the geomorphic variables was calculated (Table 4). When the whole data set was considered, the highest significant correlation was found between channel slope and specific stream power $(r=0.93, p<0.001)$, followed by the correlation between valley width and confinement $(r=0.83$, $p<0.001$ ). When the rivers were considered individually, these values decreased slightly on average for the relation between slope and specific stream power $(r>0.76, p<0.05)$ valley width and confinement $(r>0.69, p<0.05)$. According to these results, S3 (confinement and channel slope) and S4 (confinement and specific stream power) should provide similar results, followed by S4 (confinement and specific stream power) and S5 (valley width and specific stream power).

Looking for segmentation similarities to verify these correlation results, the number of common breakpoints detected in each pair of segmentations was compared. Additionally, we estimated the percentage that common breakpoints represent within the total number of breakpoints found by each pair of segmentations considered (e.g., S3 and S4 detected 59 and 63 breakpoints, respectively, 35 of which were coincident in both approaches, and $40 \%$ of which are common to both segmentations). The results showed that the higher the correlation between variables, the higher the number of coincidences in the location of breakpoints, (Kruskal-Wallis test, $p<0.05$ ). S3 and S4, S4 and S5, and S2 and S3 presented the highest proportion of coincidences (42.7\%; 39.1\%; $31.1 \%$ of the breakpoints were common of each pair of approaches, respectively), and these coincidences were significantly higher than in the rest of the pairwise comparisons.

\subsection{General variability and internal homogeneity of segments}

We found that the internal variation $\left(\mathrm{CV}_{\text {intra }}\right)$ related to the total variation $\left(\mathrm{CV}_{\text {non-aggreg }}\right)$ was reduced $>30 \%$ in all applied segmentations, with reductions up to $77 \%$ for the included variables. Additionally, we also found a reduction of the internal variability of the variables not involved in the respective segmentation run (Table 5). Moreover, the coefficient of variation of the spatially-aggregated (i.e., segments) data set $\left(\mathrm{CV}_{\text {aggreg }}\right)$ generally remained closer to the variation in the nonaggregated (i.e., $200 \mathrm{~m}$ long) data set $\left(\mathrm{CV}_{\text {non-aggreg }}\right)$. Thus, in each segmentation run, the internal variability of segments was lower than the general variability of the entire system. While the general variability is maintained, then we can assume that after the all segmentations, the system representativeness is preserved. Table 5 displays more differences of data between columns (variables) than between files (segmentations). Channel slope and valley width showed higher reduction in variability within the segments ( $>70 \%$ in reduction when these variables where considered in the respective segmentation run), whereas specific stream power, confinement and active channel width were less affected $(>45 \%)$. In this case, we could infer that S4 would be less efficient in reducing segment internal variability regarding variables used in the segmentation. The results show that the internal homogeneity of segments was not related with the initial variability of involved variables. The highest variability reductions were reached by the least and the most homogeneous variables (i.e., valley width and channel slope, respectively). A higher number of segments (e.g., S5) did not imply a higher reduction in their internal variability.

\subsection{Performance of segmentations at predicting gravel bars}

The suitability of segmentations was assessed by comparing the ability of each one (S1 to S5) to predict forms and processes, in our case the occurrence of bare and vegetated gravel bars. The results of the GAM models are shown in Fig. 4, where the percentage of deviance explained by the models predicting the occurrence of bare gravels and vegetated bars has been represented. All models based on spatiallyaggregated data sets outperformed the results based on initial data sets (i.e., values measured in each $200 \mathrm{~m}$ long unit). When the whole data set from the studied rivers was considered, vegetated bars were better predicted than bare gravel bars in both aggregated (from segments) and non-aggregated (from units $200 \mathrm{~m}$ long) data sets. The highest performance in terms of deviance explained was attained by S2 (S, ACW, VW) followed by S1 (S, ACW) for bare landforms $(58.0 \%$ and $53.2 \%$, respectively). In the case of vegetated bars, the difference between segmentation performance was less consistent in both data sets (i.e., aggregated and non-aggregated). These findings indicated that spatial aggregation by segmentation procedures using basic geomorphic variables, although always representing a simplification of the river system, still maintained the representativeness of the main features determining fluvial processes, which in our case were revealed by the occurrence of bare gravel and vegetated bars.

\subsection{Flow regulation influencing segmentation results}

Finally, we explored if flow regulation could change the ability of models to predict the occurrence of bare gravel bars and vegetated 

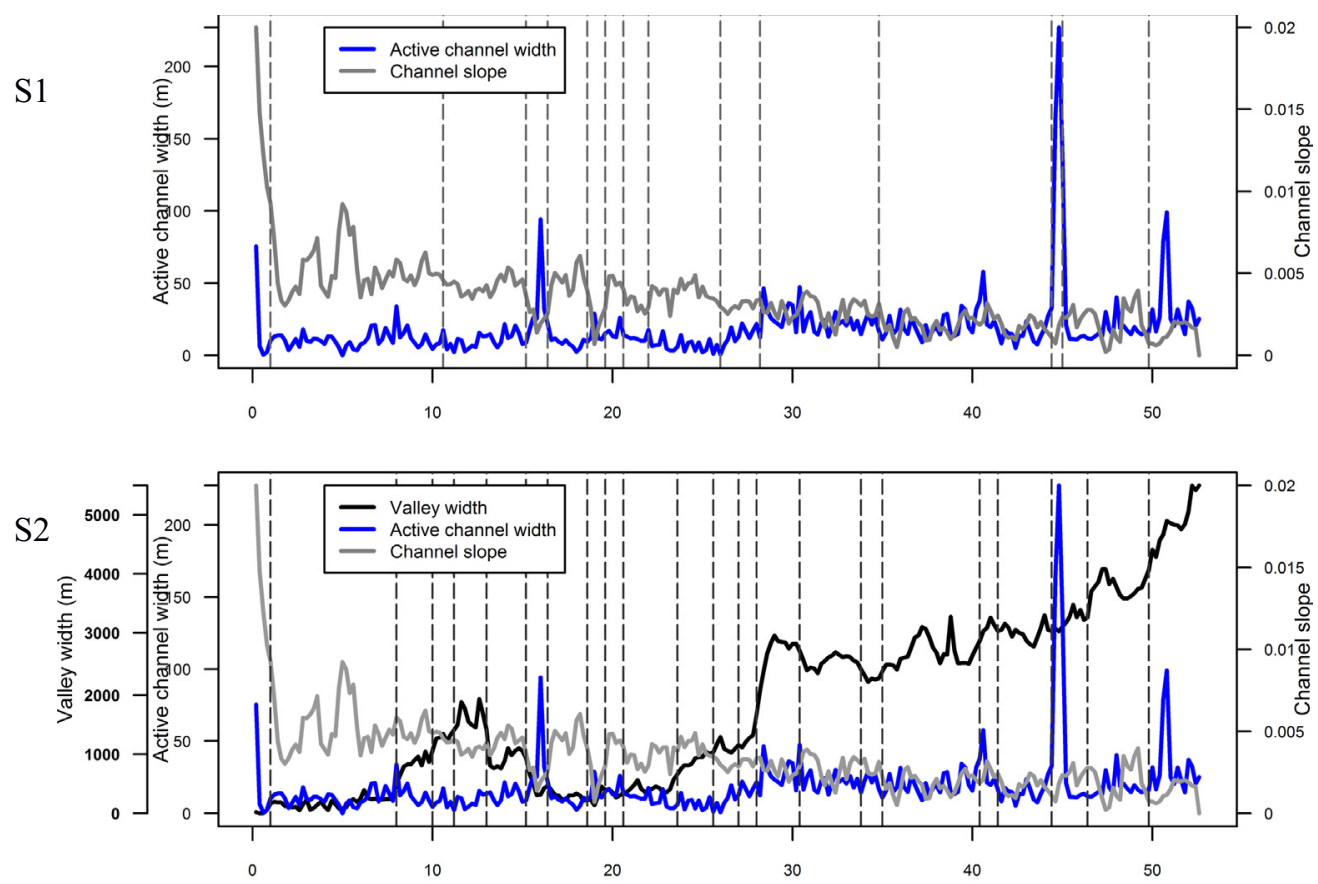

S3
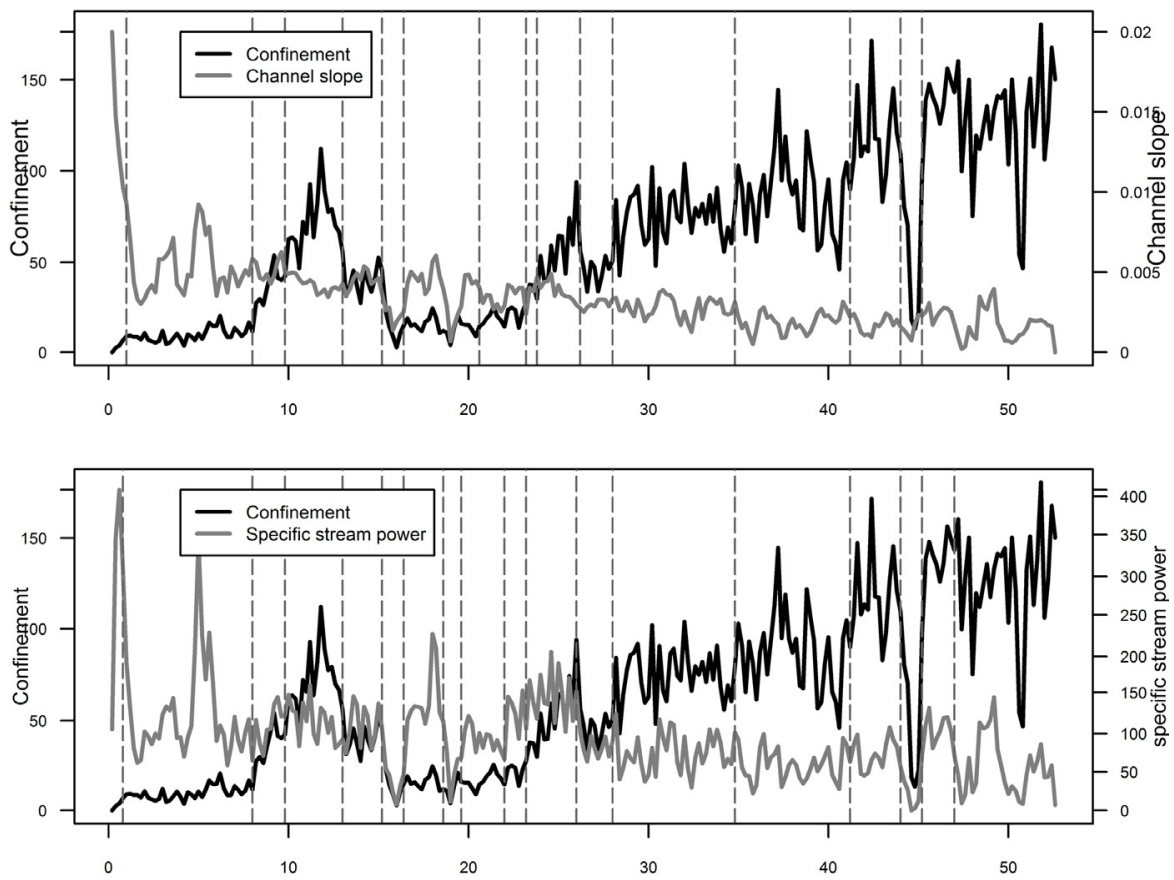

S4

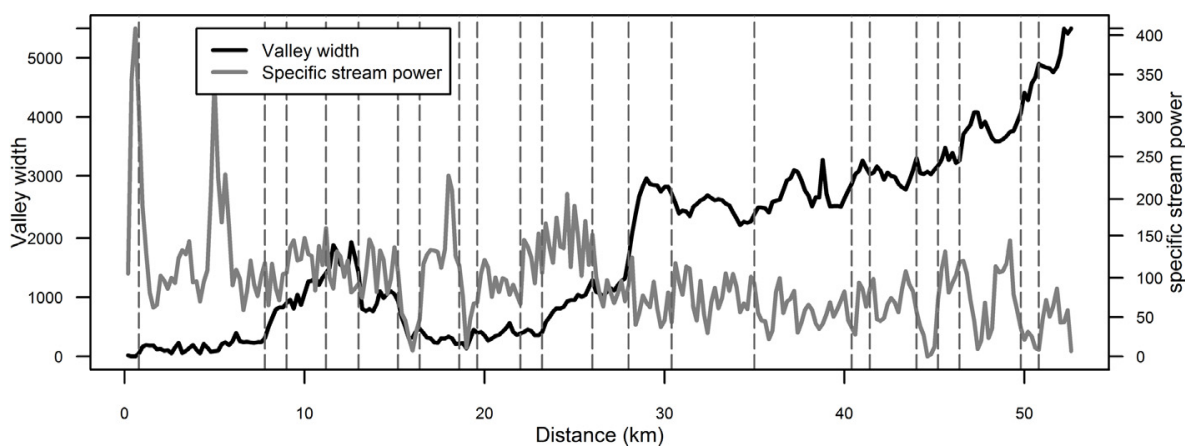

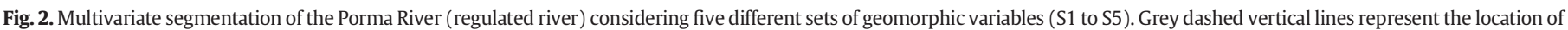
break points. 
S1

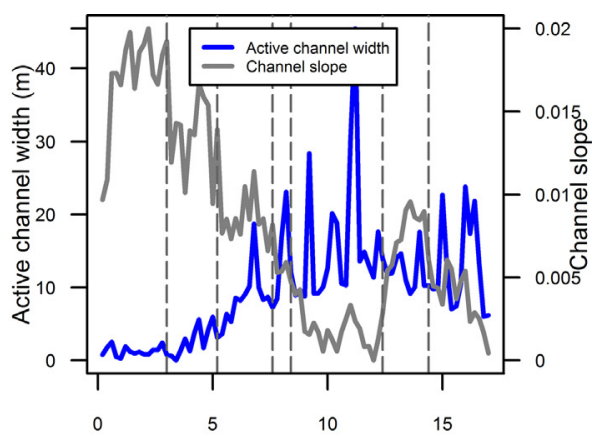

S2

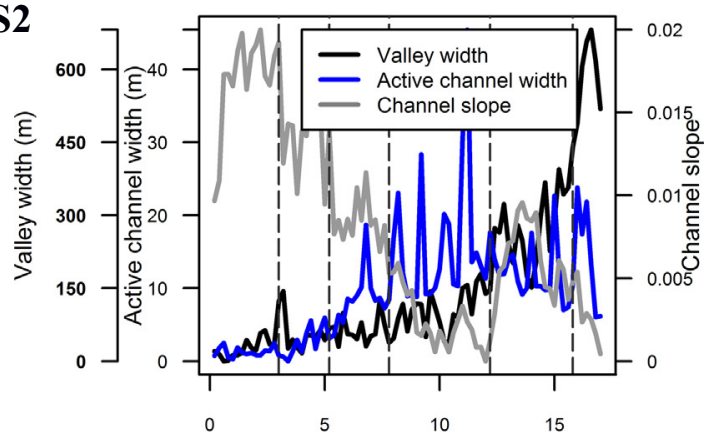

S3

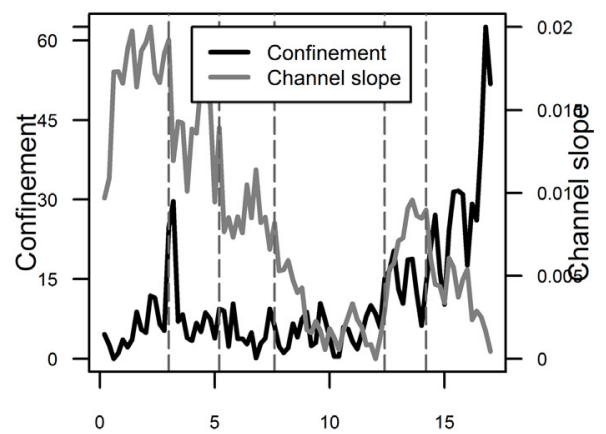

S4

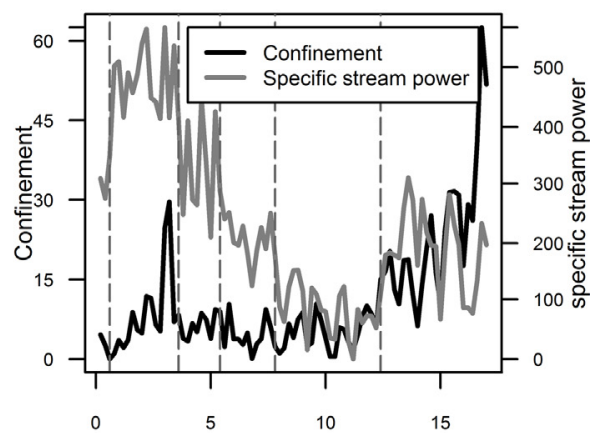

S5

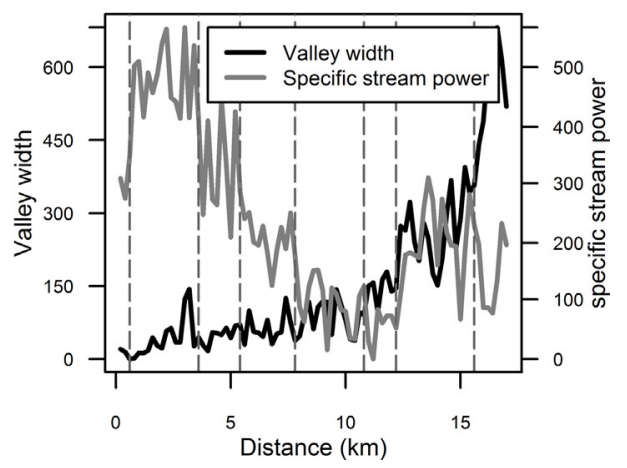

Fig. 3. Multivariate segmentation of the Yuso River (non-regulated river) considering five different sets of geomorphic variables ( 1 to S5). Grey dashed vertical lines represent the location of break points.
Table 4

Correlation matrix of the variables used in the segmentation procedure considering the whole data set: VW (valley width), ACW (active channel width), S (slope), C (confinement) and $\omega$ (specific stream power). In bold type, significant correlations $>0.8$.

\begin{tabular}{lllll}
\hline & ACW & S & $C$ & $\omega$ \\
\hline VW & $0.43^{* * *}$ & $-0.49^{* * *}$ & $\mathbf{0 . 8 3}^{* * *}$ & $-0.45^{* * *}$ \\
ACW & & $-0.43^{* * *}$ & $0.07^{*}$ & $-0.49^{* * *}$ \\
S & & & $-0.40^{* * *}$ & $\mathbf{0 . 9 3 ^ { * * * }}$ \\
C & & & & $-0.32^{* * *}$ \\
\hline
\end{tabular}

Note: Significance after Spearman test $(p<0.05)$ :

*** $p<0.001$.

* $p<0.05$.

bars. We split the whole set of segments into two groups (i.e., nonregulated and regulated segments) in Fig. 5. Again, models based on spatially-aggregated data sets outperform models based on nonaggregated data sets (values measured every $200 \mathrm{~m}$ ). The percentage of the deviance explained by the models when considering the aggregated data set increased more in non-regulated segments than in the regulated ones. In particular, the segmentations that include the active channel width as a variable (i.e., S1 and S2) provided the best results, for both bare gravel and vegetated bars. In the case of regulated reaches, the increase in model performance was poorer in all cases, with better results for segmentations that include specific stream power (S4 and S5).

Finally, we added the variable IR (impoundment ratio) to the models as a descriptor of the segment (category Aggreg $+I R$ in Fig. 6) and repeated the analysis. All segmentation runs ( $\mathrm{S} 1$ to $\mathrm{S} 5$ ) increased the explained deviance (Kruskal-Wallis test, $p<0.05$ ) when predicting bare gravel bars. The most improvement was attained by those considering specific stream power (S4 and S5 increased the explained deviance $30.8 \%$ and $57.0 \%$, respectively), although S2 followed by S1 again attained the best result ( $74.7 \%$ and $69.1 \%$, respectively). In the case of vegetated bars, the incorporation of IR as a descriptor did not significantly improve model performance nor indicate differences among segmentations.

\section{Discussion}

\subsection{Differences across segmentations regarding the influence of the set of variables}

Our results showed that the selection of geomorphic variables influences segmentation results. Each tested segmentation provided different results for the number of segments per kilometer and their average length, but whereas the differences were significant between rivers, they were not significant across segmentations (i.e., among different sets of geomorphic variables).

The number of the resultant segments ranged from 60 (S1 using S and ACW) to 95 (S5 using VW and SSP). A larger number of segments (e.g., S5) did not imply higher internal segment homogeneity. In all cases, the internal segment variation was reduced (i.e., $\mathrm{CV}_{\text {intra }}$ ), while the variation along the system considering segment characteristics was maintained ( $\left.\mathrm{CV}_{\text {aggreg }}\right)$. Therefore, all types of aggregations applied seem to be a valid, geomorphic-based first step for further river characterization, environmental assessment and diagnosis (González del Tánago et al., 2016a, 2016b; Rinaldi et al., 2016), and also may represent the initial basis for further aggregation/disaggregation procedures applied at a regional network scale (Alber and Piégay, 2011).

Our results reinforce previous statements advocating for the use of automatic procedures to delineate homogeneous river reaches for monitoring programmes, modelling, ecological assessment or biophysical characterization at different scales (Brenden et al., 2008; Alber and Piégay, 2011; Bizzi and Lerner, 2012). This should be explanatory or complementary to other approaches that define river reaches according to discrete criteria that may be subjective (e.g., fixed river length) or 
Table 5

Average reduction (\%) in the internal variation in the applied segmentations (S1 to S5) calculated for each variable as $\left.\left(\mathrm{CV}_{\text {non-aggreg }}-\mathrm{CV}_{\text {intra }}\right) / \mathrm{CV}_{\text {non-aggreg }}\right)$. In parentheses, average variation conserved after segmentations calculated as the ratio $\left(\mathrm{CV}_{\text {aggreg}} / \mathrm{CV}_{\text {non-aggreg}}\right)$. Shaded cells correspond to variables not considered in the respective segmentation run. The first line of the table shows the coefficient of variation (\%) of each variable before aggregation, as the reference.

\begin{tabular}{lccccc}
\hline & $\begin{array}{c}\text { Active channel } \\
\text { width }\end{array}$ & Slope & Valley width & Confinement & $\begin{array}{c}\text { Specific Stream } \\
\text { Power }\end{array}$ \\
\hline CV non-aggreg & 99.3 & 93.7 & 126.0 & 105.8 & 99.1 \\
\hline S1 & $54.8(1.07)$ & $71.6(1.02)$ & $63.6(1.09)$ & $50.2(0.98)$ & $47.5(0.98)$ \\
S2 & $55.3(0.91)$ & $77.4(1.05)$ & $73.6(0.98)$ & $58.8(0.87)$ & $46.7(1.0)$ \\
S3 & $51.2(0.91)$ & $71.1(1.0)$ & $67.5(1.08)$ & $57.1(0.91)$ & $43.1(0.95)$ \\
S4 & $57.3(0.79)$ & $70.4(1.04)$ & $68.0(1.12)$ & $57.5(0.99)$ & $47.3(0.98)$ \\
S5 & $57.1(0.74)$ & $62.7(1.09)$ & $74.7(0.97)$ & $58.7(0.96)$ & $47.8(1.04)$ \\
\hline
\end{tabular}

need expert-criteria (e.g., observed channel changes) (Rinaldi et al., 2013; Gurnell et al., 2016). Although natural processes, both biotic and abiotic, frequently operate on larger spatial scales, and localised, non-continuous analysis and sampling lead to a fundamental mismatch of scales between the studied processes and the considered "segments" (Fausch et al., 2002), segmentation approaches may provide a useful compromise between point-based assessments and continuum riverscape analysis. In this sense, remotely sensed data and statistical analyses may facilitate river data acquisition and management, and greatly help scientists and managers in assessing human pressures and impacts or channel responses to restoration efforts (Carbonneau et al., 2012; Carbonneau and Piégay, 2012).

As a further insight when using multivariate approaches, our research highlighted the influence of the selected variables on the segmentation results. In previous studies, different sets of variables have been used to characterize and segment river systems, from primary geomorphic variables such as the convexity of the long profile to infer fluvial processes and human interventions (Harmar and Clifford, 2007) to more complex and derived variables such as stream power to characterize physical habitats (Bizzi and Lerner, 2012). According to our results, we can argue that the selection of variables considered for river segmentation should be adequately weighed according to the aims of the study. We found that the number and location of boundaries between segments fluctuates according to the variables considered, and that the information gained when using secondary variables is not always justified compared to the time and effort expended for their acquisition.

We have considered three primary geomorphic variables frequently studied in river morphology (active channel width, channel slope and valley width) that can be extracted directly from available digital information compared to the two secondary geomorphic variables (confinement and specific stream power) whose calculation requires further effort. Active channel and valley widths are frequently manually

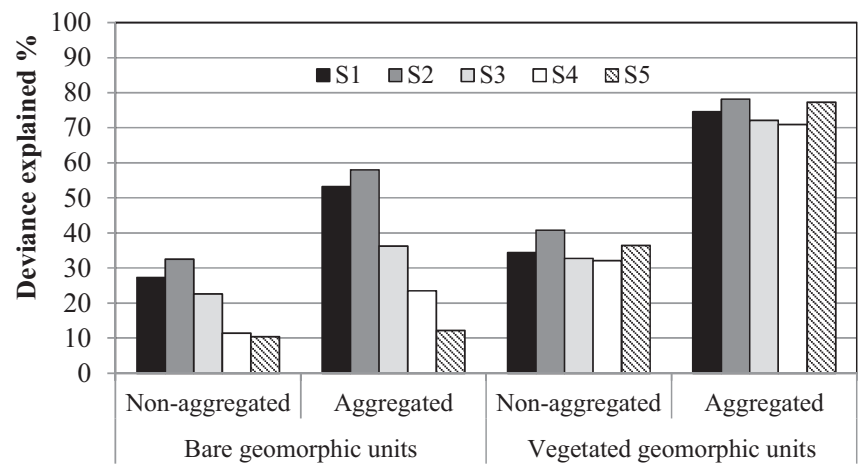

Fig. 4. Model performance of the different segmentations (S1-S5) predicting the occurrence of bare gravel and vegetated bars, for the non-aggregated and aggregated data sets. digitized on the aerial orthophotographs, which could require more time to collect than the use of empirical relationships (Bizzi and Lerner, 2012, 2015), but the results harbour less uncertainty. Channel slope is normally calculated from a DEM, which should be considered carefully, especially in the case of shallow slopes (Lane and Chandler, 2003), and frequently needs corrections (Jain et al., 2006), yet it is easily measured and implies straightforward processes. In contrast, secondary variables like channel confinement require the calculation of ratios between two previously obtained variables (i.e., active channel and valley width). Calculation of specific stream power at the network scale also requires additional discharge data, which inevitably incorporates other sources of uncertainty and much more effort.

In our study site, segmentations using more complex secondary variables (i.e., S4, S5) did not significantly improve the representativeness of the fluvial system in comparison with segmentations using primary variables (i.e., S1, S2). Taking into account the necessary trade-off between costs (e.g., time consumption) and efficiency (gained information), we advocate for careful variable selection, prioritizing the use of primary geomorphic variables over secondary variables (Bizzi and Lerner, 2012; Schmitt et al., 2014). Our results suggest that these more complex variables may not necessarily provide better results or relevant additional insight into the river network, although their use must be conditioned by the aims and context of the research.

Correlation between involved geomorphic variables seems to determine similarity among segmentations. The highest correlation between channel slope $(S)$ and specific stream power $(\omega)(r=0.93, p<0.001)$ led S3 $(S, C)$ and S4 $(\omega, C)$ to be highly coincident. Almost half of the segments were detected in S3 without the additional effort of inferring discharges from extrapolations and empirical relationships to derive local values of the specific stream power required in S4. Similarly, the high correlation between confinement (C) and valley width (VW) $(r=0.83, p<0.001)$, led S2 (ACW, VW, S) and S3 (C, S) to share the third part of the segments. According to these results we could conclude that channel slope can act as an efficient surrogate variable for stream power, influencing segmentation results in a similar way but with much less effort to measure.

\subsection{Predicting fluvial geomorphic units from automatic delineation of river reaches}

Our results suggest that automatic segmentation procedures not only allow one to discretize the river continuum in relatively homogeneous segments based on river forms, but help predict the occurrence of certain geomorphic units that reflect river processes. Geomorphic units such as in-channel gravel bars have been considered by many authors as strong indicators of river dynamics (Brierley and Fryirs, 2005; González del Tánago et al., 2016a, 2016b). The occurrence of lateral and mid-channel gravel bars directly reflects sediment supply conditions under a range of flow energy and bed material textures. Bare gravel bars occur where an excess of the coarse bedload fraction can no longer be transported by current flows (Church and Jones, 1982). 


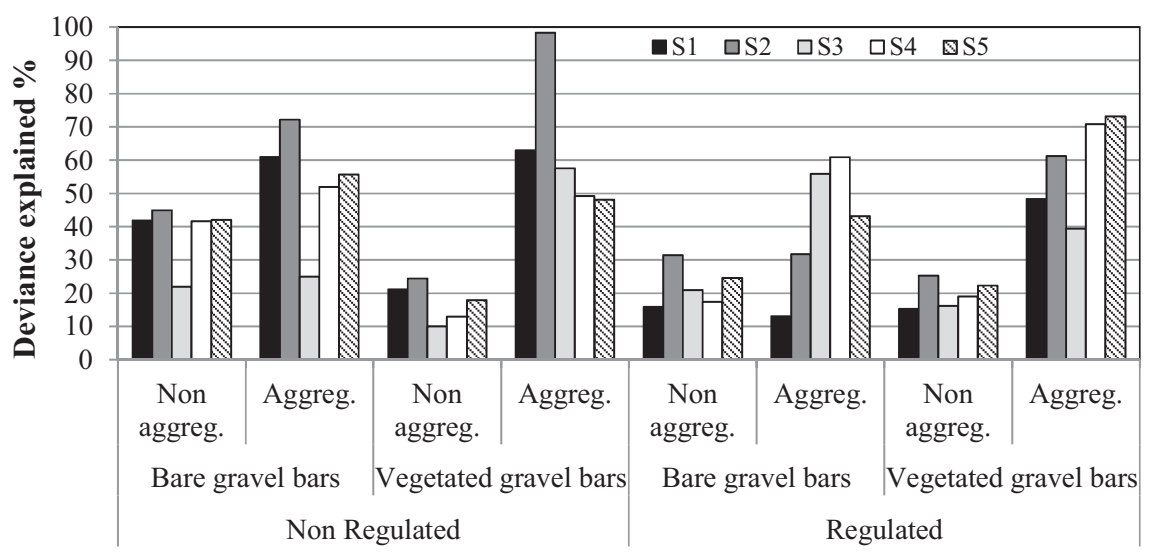

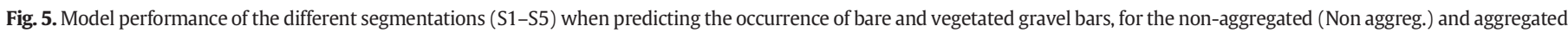
(Aggreg.) data sets, and considering two sets of segments: non-regulated and regulated segments.

They are characteristic in shallow, wide braided rivers, where coarse sediments are deposited across the channel bed. Vegetated gravel bars introduce additional depositional features as a consequence of vegetation colonization enhanced by flow regime changes or channel migration. They are more frequent in regulated rivers where vegetation encroachment takes place (Lobera et al., 2015).

The segmentation procedures used in this research performed better when predicting the occurrence of vegetated bars than bare gravel bars. The differences across segmentations were much more relevant for bare gravel bars than for vegetated bars. Those segmentations taking into account active channel width and channel slope (i.e., S1 and S2) produced the best predictions for bare gravel bars. These results are in agreement with previous findings by Martínez-Fernández et al. (2016a) who analysed the potential use of geomorphic variables (i.e., stream power, channel slope, active channel width and valley confinement) for predicting the occurrence of bare gravel and vegetated bar areas in the Curueño River, considered in this study. A close correlation between active channel width and bare gravel areas at the reach scale was found in the Curueño River, showing that although river energy is one of the main drivers rearranging the gravel bars at the watershed scale (Bizzi and Lerner, 2015; Brierley and Fryirs, 2005), other smaller-scale factors such as valley confinement, which indirectly determines the transversal dimension of the channel exposed by the active channel width, determine the local configuration and deposition of gravel bars. Again, our findings indicated that S1 and S2 (active channel width, channel slope and valley width) generally outperformed other segmentations when predicting the distribution of bare gravel and vegetated bars.

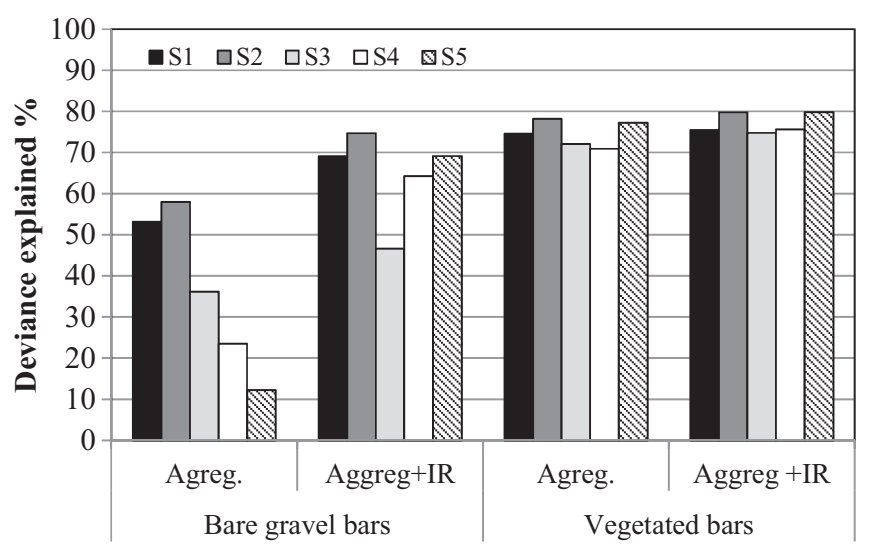

Fig. 6. Model performance of the different segmentations (S1-S5) when predicting the occurrence of bare and vegetated gravel bars, for the aggregated data set without considering (Aggreg) and IR as an explicative variable (Aggreg $+I R)$.

\subsection{Flow regulation influencing segmentation results}

Our findings indicated that flow regulation changed the efficiency of geomorphic variables determining geomorphic units (e.g., gravel bars). Segmentations involving slope and active channel width (i.e., S1 and S2) outperformed the other segmentations in the case of non-regulated rivers, whereas in regulated rivers the best results were found for segmentations involving confinement or specific stream power (i.e., S4 and S5). In general, the deviance explained by the models decreased for regulated rivers, as an evidence for the poorer relationship between physical variables and current channel patterns in regulated rivers, which are expected from the understanding of river forms and processes under non-human-intervened conditions.

Flow regulation by dams and reservoirs that reduce the frequency of floods and coarse sediment supply has strong influence on river geomorphology (Graf, 2006; Burke et al., 2009; Grant, 2012). In particular, active channel width is highly affected by flow regulation (Brandt, 2000; Schmidt and Wilcock, 2008; González del Tánago et al., 2015, 2016b; Martínez-Fernández et al., 2017), and appears to be an accurate explanatory variable for the occurrence of bare gravel bars in nonregulated rivers (e.g., Martínez-Fernández et al., 2016a). In the case of regulated rivers, however, active channel width does not demonstrate a strong relationship with bare gravel bars whose maintenance is strongly compromised by the regulated flows (Graf, 2006; Lobera et al., 2015).

Our results suggest that automatic delineation may be influenced by flow regulation and other human pressures that alter geomorphic variables. Therefore, average values or characteristics of the segments based on these potentially altered geomorphic variables should be extrapolated with care and may help in assessing their geomorphic sensitivity and river capacity for adjustments to human pressures along the river network (Reid and Brierley, 2015; González del Tánago et al., 2016b).

\section{Conclusions}

This study compares automatic segmentation procedures to identify distinct reaches along the river continuum, using different combinations of geomorphic variables. From our results we can conclude that the number and type of variables considered in the applied segmentation procedures may influence the number of segments or the suitability of segments for predicting channel geomorphic units.

Selecting geomorphic variables for applying multivariate procedures should be done carefully to avoid wasting effort and time without improving the performance of the results. Easily quantified primary variables (i.e., channel slope and active channel width) were shown to be very efficient in providing valuable insight into river forms and 
processes. In some cases, they could be appropriate surrogate variables for other more complex and time consuming secondary variables such as stream power and valley confinement.

Flow regulation and other human disturbances may trigger channel adjustments or changes that influence natural relationships between channel forms and processes. In this sense, automatic segmentation based on channel forms may help to assess geomorphic sensitivity of rivers to channel adjustments, and facilitate the evaluation of resistance and resilience of river segments to human pressures and impacts across the entire river network.

\section{Acknowledgements}

The work leading to this paper has received funding for the EU's FP7 under Grant Agreement No. 282656 (REFORM). VMF was supported by a research grant awarded by the Spanish Government (Becas de Formación del Profesorado Universitario, BOE-A-2014-12791). We also thank the Confederación hidrográfica del Duero for supplying hydrologic data, Professor J Solana Gutiérrez (Universidad Politécnica de Madrid) for his statistical support and, finally, the anonymous reviewers and Professor Scott Lecce for their constructive remarks which allowed to improve the quality of the manuscript.

\section{Appendix A. Supplementary data}

Supplementary data to this article can be found online at https://doi. org/10.1016/j.geomorph.2019.01.005.

\section{References}

Alber, A., Piégay, H., 2011. Spatial disaggregation and aggregation procedures for characterizing fluvial features at the network-scale: application to the Rhône basin (France) Geomorphology 125 (3), 343-360.

Beechie, T.J., Sear, D.A., Olden, J.D., Pess, G.R., Buffington, J.M., Moir, H., Philip, R., Pollock M.M., 2010. Process-based principles for restoring river ecosystems. Bioscience 60 (3), 209-222

Benda, L.E.E., Poff, N.L., Miller, D., Dunne, T., Reeves, G., Pess, G., Pollock, M.M., 2004. The network dynamics hypothesis: how channel networks structure riverine habitats. AIBS Bull. 54 (5), 413-427.

Bizzi, S., Lerner, D.N., 2012. Characterizing physical habitats in rivers using map-derived drivers of fluvial geomorphic processes. Geomorphology 169, 64-73.

Bizzi, S., Lerner, D.N., 2015. The use of stream power as an indicator of channel sensitivity to erosion and deposition processes. River Res. Appl. 31 (1), 16-27.

Brandt, S.A., 2000. Classification of geomorphological effects downstream of dams. Catena 40 (4), 375-401.

Brenden, T.O., Wang, L., Seelbach, P.W., Clark, R.D., Wiley, M.J., Sparks-Jackson, B.L., 2008. A spatially constrained clustering program for river valley segment delineation from GIS digital river networks. Environ. Model. Softw. 23, 638-649.

Brierley, G.J., Fryirs, K.A., 2005. Geomorphology and River Management: Applications of the River Styles Framework. Blackwell, Oxford.

Burke, M., Jorde, K., Buffington, J.M., 2009. Application of a hierarchical framework for assessing environmental impacts of dam operation: changes in streamflow, bed mobility and recruitment of riparian trees in a western North American river. J. Environ. Manag. 90, S224-S236.

Carbonneau, P., Piégay, H., 2012. Fluvial Remote Sensing for Science and Management. Wiley-Blackwell, West-Sussex (435 pp.).

Carbonneau, P., Fonstad, M.A., Marcus, W.A., Dugdale, S.J., 2012. Making riverscapes real. Geomorphology 137 (1), 74-86.

Church, M., Jones, D., 1982. Gravel-bed rivers. Sediment Cascades: An Integrated Approach, pp. 241-269.

Demarchi, L, Bizzi, S., Piégay, H., 2017. Regional hydromorphological characterization with continuous and automated remote sensing analysis based on VHR imagery and low-resolution LiDAR data. Earth Surf. Process. Landf. 42 (3), 531-551.

Faraway, J.J., 2006. Extending the Linear Models with R: Generalized Linear, Mixed Effects and Nonparametric Regression Models. Chapman and Hall.

Fausch, K.D., Torgersen, C.E., Baxter, C.V., Li, H.W., 2002. Landscapes to riverscapes: bridging the gap between research and conservation of stream fishes. AIBS Bull. 52 (6), 483-498.

Frissell, C.A., Liss, W.J., Warren, C.E., Hurley, M.D., 1986. A hierarchical framework for stream habitat classification: viewing streams in a watershed context. Environ. Manag. 10 (2), 199-214.

González del Tánago, M., Bejarano, M.D., García de Jalón, D., Schmidt, J.C., 2015. Biogeomorphic responses to flow regulation and fine sediment supply in Mediterranean streams (the Guadalete River, southern Spain). J. Hydrol. 528, 751-762.

González del Tánago, M., Gurnell, A.M., Belletti, B., García de Jalón, D., 2016a. Indicators of river system hydromorphological character and dynamics: understanding current conditions and guiding sustainable river management. Aquat. Sci. 78 (1), 35-55.
González del Tánago, M., Martínez-Fernández, V., García de Jalón, D., 2016b. Diagnosing problems produced by flow regulation and other disturbances in Southern European Rivers: the Porma and Curueño Rivers (Duero Basin, NW Spain). Aquat. Sci. 78 (1), 121-133.

Graf, W.L., 2006. Downstream hydrologic and geomorphic effects of large dams on American rivers. Geomorphology 79 (3), 336-360.

Grant, G.E., 2012. The geomorphic response of gravel-bed rivers to dams: perspectives and prospects. In: Church, M., Biron, P.M., Roy, A.G. (Eds.), Gravel-bed Rivers: Processes, Tools, Environments. John Wiley \& Sons, Ltd., Chichester, UK, pp. 165-181.

Guertault, L., Camenen, B., Paquier, A., Peteuil, C., 2018. A one-dimensional process-based approach to study reservoir sediment dynamics during management operations. Earth Surf. Process. Landf. 43 (2), 373-386.

Gurnell, A.M., Rinaldi, M., Belletti, B., Bizzi, S., Blamauer, B., Braca, G., Buijse, A.D., Bussettini, M., Camenen, B., Comiti, F., Demarchi, L., García de Jalón, D., González del Tánago, M., Grabowski, R.C., Gunn, I.D.M., Habersack, H., Hendriks, D., Henshaw, A.J., Klösch, M., Lastoria, B., Latapie, A., Marcinkowski, P., Martínez- Fernández, V., Mosselman, E., Mountford, J.O., Nardi, L., Okruszko, T., O'Hare, M.T., Palma, M., Percopo, C., Surian, N., van de Bund, W., Weissteiner, C., Ziliani, L., 2016. A multi-scale hierarchical framework for developing understanding of river behaviour to support river management. Aquat. Sci. 78, 1-16.

Habersack, H.M., 2000. The river-scaling concept (RSC): a basis for ecological assessments. Hydrobiologia 422 (423), 49-60.

Harmar, O.P., Clifford, N.J., 2007. Geomorphological explanation of the long profile of the lower Mississippi River. Geomorphology 84 (3-4), 222-240.

Jain, V., Preston, N., Fryirs, K., Brierley, G., 2006. Comparative assessment of three approaches for deriving stream power plots along long profiles in the upper Hunter River catchment, New South Wales, Australia. Geomorphology 74 (1), 297-317.

Knighton, A.D., 1999. Downstream variation in stream power. Geomorphology 29, 293-306.

Kruskal, W.H., Wallis, W.A., 1952. Use of ranks on one criterion variance analysis. J. Am. Stat. Assoc. 47, 583-621.

Lane, S.N., Chandler, J.H., 2003. Editorial: the generation of high quality topographic data for hydrology and geomorphology: new data sources, new applications and new problems. Earth Surf. Process. Landf. 28, 229-230.

Leviandier, T., Alber, A., Le Ber, F., Piégay, H., 2012. Comparison of statistical algorithms for detecting homogenous river reaches along a longitudinal continuum. Geomorphology $138,130-144$.

Livingstone, D.J., 2009. A Practical Guide to Scientific Data Analysis. Wiley, Chichester, UK.

Lobera, G., Besné, P., Vericat, D., López-Tarazón, J.A., Tena, A., Aristi, I., Díez, J.R., Ibisate, A., Larrañaga, A., Elosegi, A., Batalla, R.J., 2015. Geomorphic status of regulated rivers in the Iberian Peninsula. Sci. Total Environ. 508, 101-114.

Martínez-Fernández, V., González del Tánago, M., García de Jalón, D., 2016a. The use of stream power as an indicator of geomorphological processes. In: Durán Valsero, J.J. Montes Santiago, M., Robador Moreno, A., Salazar Rincón, A. (Eds.), Comprendiendo el relieve: del pasado al futuro. Instituto Geológico y Minero de España, Madrid, pp. 357-364.

Martínez-Fernández, V., Solana-Gutiérrez, J., González del Tánago, M., García de Jalón, D., 2016b. Automatic procedures for river reach delineation: univariate and multivariate approaches in a fluvial context. Geomorphology 253, 38-47.

Martínez-Fernández, V., González del Tánago, M., Maroto, J., García de Jalón, D., 2017. Fluvial corridor changes over time in regulated and non-regulated rivers (Upper Esla River, NW Spain). River Res. Appl. 33 (2), 214-223.

Mielke, P.W., 1991. The application of multivariate permutation methods based on distance functions in the earth sciences. Earth Sci. Rev. 31, 55-71.

Montgomery, D.R., 1999. Process domains and the river continuum. J. Am. Water Resour. Assoc. 25 (2), 397-410.

Orlowski, L.A., Grundy, W.D., Mielke Jr., P.W., Schumm, S.A., 1993. Geological applications of multi-response permutation procedures. Math. Geol. 25 (4), 483-500.

Parker, C., Clifford, N.J., Thorne, C.R., 2012. Automatic delineation of functional river reach boundaries for river research and applications. River Res. Appl. 28 (10), $1708-1725$.

Piégay, H., Alber, A., Lauer, J.W., Rollet, A.J., Wiederkehr, E., 2012. Biophysical characterisation of fluvial corridors at reach to network scales. In: Carbonneau, P.E., Piégay, H. (Eds.), Fluvial Remote Sensing for Science and Management. John Wiley-Blackwell, Chichester, U.K., pp. 241-269.

R Core Team, 2017. R: A Language and Environment for Statistical Computing. R Foundation for Statistical Computing, Vienna, Austria http://www.R-project.org/.

Reid, H.E., Brierley, G.J., 2015. Assessing geomorphic sensitivity in relation to river capacity for adjustment. Geomorphology 251, 108-121.

Reinfelds, I., Cohen, T., Batten, P., Brierley, G., 2004. Assessment of downstream trends in channel gradient, total and specific stream power: a GIS approach. Geomorphology 60 (3), 403-416.

Rinaldi, M., Surian, N., Comiti, F., Bussettini, M., 2013. A method for the assessment and analysis of the hydromorphological condition of Italian streams: the Morphological Quality Index (MQI). Geomorphology 180, 96-108.

Rinaldi, M., Gurnell, A.M., González del Tánago, M., Bussettini, M., Hendriks, D., 2016. Classification of river morphology and hydrology to support management and restoration. Aquat. Sci. 78 (1), 17-33.

Rivas Casado, M., González, R.B., Ortega, J.F., Leinster, P., Wright, R., 2017. Towards a transferable UAV-based framework for river hydromorphological characterization. Sensors 17 (10), 2210

Schmidt, J.C., Wilcock, P.R., 2008. Metrics for assessing the downstream effects of dams. Water Resour. Res. 44 (4)

Schmitt, R., Bizzi, S., Castelletti, A., 2014. Characterizing fluvial systems at basin scale by fuzzy signatures of hydromorphological drivers in data scarce environments. Geomorphology 214, 69-83. 
Seelbach, P.W., Wiley, M.J., Baker, M.E., Wehrly, K.E., 2006. Initial classification of river valley segments across Michigan's Lower Peninsula. In: Hughes, R.M., Wang, L., Seelbach, P.W. (Eds.), Landscape Influences on Stream Habitats and Biological Assemblages. American Fisheries Society, Bethesda, Maryland, pp. 25-48.

Wood, S., 2015. mgcv: mixed GAM computation vehicle with GCV/AIC/REML smoothness estimation. Available at. https://cran.r-743project.org/web/packages/mgcv/index. html, Accessed date: January 2018.
Yochum, S.E., Sholtes, J.S., Scott, J.A., Bledsoe, B.P., 2017. Stream power framework for predicting geomorphic change: the 2013 Colorado Front Range flood. Geomorphology 292, 178-192.

Zuur, A.F., Ieno, E.N., Walker, N.J., Saveliev, A.A., Smith, G.M., 2009. Mixed Effects Models and Extensions in Ecology with R. Springer, New York (574 pp). 